\section{Chasing Quality-Clinical Practice Guidelines and HEDIS Measures of Asthma and Depression Therapy Management}

In this issue of JMCP are 4 articles that examine aspects of evidence-based medicine (EBM) in 4 different clinical pathways. Payakachat, Summers, and Barbuto compare the evidence and 6 clinical practice guidelines for the treatment of epilepsy published between 2000 and 2005. ${ }^{1}$ Heaton et al. challenge the value of leukotriene modifiers, currently recommended as second-line therapy in the treatment of asthma. ${ }^{2}$ Robinson et al. found an above-average rate of adherence to one of the quality measures in the Health Plan Employer Data and Information Set (HEDIS) in the treatment of depression. ${ }^{3}$ Winterbottom et al. found a low rate of adherence to a clinical practice guideline for the use of gabapentin for neuropathic pain in usual care versus a clinical pharmacy consult. ${ }^{4}$

In the treatment of depression, drug therapy is about as effective as psychotherapy, ${ }^{5}$ but patients with major depression can be stratified to predict better response to psychotherapy versus drug therapy or the combined therapy. ${ }^{6}$ In one of the few studies that directly compared cognitive-behavioral therapy (CBT) with drug therapy, the Treatment for Adolescents with Depression Study (TADS) team found placebo effective in about $35 \%$ of patients with major depressive disorder compared with about a $43 \%$ response to CBT, $61 \%$ response to the selective serotonin reuptake inhibitor (SSRI) fluoxetine, and $71 \%$ response to combined CBT and fluoxetine. ${ }^{7}$ In this randomized controlled trial (RCT) of a volunteer sample of 439 patients between the ages of 12 to 17 years with a primary Diagnostic and Statistical Manual of Mental Disorders, Fourth Edition (DSM-IV), diagnosis of major depressive disorder, 12 weeks of fluoxetine alone (10-40 mg per day) was compared with CBT alone, CBT with fluoxetine (10-40 mg per day, and placebo). The combined treatment of $\mathrm{CBT}$ and fluoxetine was superior to fluoxetine alone $(P=0.02)$ and to $\mathrm{CBT}$ alone $(P=0.01)$.

Drug therapy alone for the treatment of major depression is not much more effective than placebo, but the magnitude of the difference varies among clinical trials. ${ }^{8}$ For fluoxetine, the only antidepressant with evidence of effectiveness and favorable benefit-risk ratio in children and adolescents, ${ }^{9}$ Emslie et al. found a $56 \%$ response rate in depressed children and adolescents versus a $33 \%$ response rate for placebo, ${ }^{10}$ response rates similar to TADS (above). This study by Emslie et al. was an RCT funded by the National Institute of Mental Health and published in 1997. In research in a similar population of patients funded by the manufacturer of fluoxetine and published 5 years later, Emslie et al. found a $65 \%$ response to fluoxetine versus $53 \%$ for placebo. ${ }^{11}$ Remission of symptoms occurred in 31\% of fluoxetine patients versus $23 \%$ for placebo in the earlier study and in $41 \%$ of fluoxetine patients versus $20 \%$ of placebo patients in the later study. In other words, the placebo response ranged from 33\% to $53 \%$ in these 2 clinical trials in children and adolescents and in the TADS study in adults, and complete remission of symptoms with placebo ranged from $20 \%$ to $23 \%$ of children and adolescent patients in the latter 2 clinical trials of fluoxetine.

In a meta-analysis of original data from 7 RCTs, Thase et al. found that $51 \%$ of outpatients with major depressive disorder responded to placebo and 36\% of the patients randomized to placebo experienced remission during follow-up. ${ }^{12}$ Hjalmarsson et al. concluded that RCT studies in depressed patients show placebo response rates in the range of 30\% to 50\%, active drug response in the range of $45 \%$ to $50 \%$, and the difference between active drug and placebo response rates in the range of $18 \%$ to $25 \% \cdot{ }^{13}$ Other researchers have suggested that the high placebo response rates in the latter (2002) study by Emslie may be associated with the relatively low depression scores for the patients involved in that study, and Khan et al. found that patients with more-severe depression respond better to antidepressant therapy. ${ }^{14}$ Separately, Khan et al. found, from their review of 15 RCTs, that women exhibit greater response to SSRI antidepressants than men. ${ }^{15}$

In the ARTIST (A Randomized Trial Investigating SSRI Treatment) study, $46 \%$ of patients ( $\mathrm{n}=256$ ) with major depressive disorder treated with an SSRI were nonresponders at 6 months, and $53 \%$ of the patients $(n=222)$ who received SSRI therapy for at least 6 months did not achieve remission. ${ }^{16}$ The results of this prospective naturalistic trial suggest that effective treatment of depression involves more than adherence (continuation) of drug therapy. For cost outcomes, Eaddy et al. found, from administrative claims data, that total medical costs were not lower for patients who take SSRIs or other antidepressants for 90 days or longer compared with persons who take antidepressants for fewer than 90 days. ${ }^{17}$

So, the accumulated evidence suggests that antidepressants are little more effective than placebo (although antidepressants appear to be more effective than placebo in patients with more-severe depression), are generally no more effective than psychotherapy, at least one half of depressed patients who take SSRIs for at least 6 months will not achieve remission, and taking antidepressants for 90 days or longer is not associated with savings in total medical costs. In light of this evidence and the absence of a measure of disease severity, the HEDIS measures of clinical quality for the treatment of depression may require further revision.

There is evidence that interventions as limited as telephone talk therapy can improve clinical outcomes in depression disease management. In a study of 600 patients beginning antidepressant treatment for depression in 7 group-model primary care clinics, a structured 8-session talk therapy program delivered by telephone was superior to usual care as measured by Hopkins Symptom Checklist Depression Scale depression scores $(P=0.02)$, the proportion of patients reporting that depression was "much improved" ( $80 \%$ vs. $55 \%, P<0.001$ ), and in the proportion of patients "very satisfied" with depression treatment (59\% vs. 
$29 \%, P<0.001) .{ }^{18}$ Quality of care for the treatment of depression involves more than antidepressant medication management (AMM).

What can the research performed with administrative claims data such as that reported by Robinson et al. in this issue of JMCP add to the clinical trial data? As pointed out by a clinical psychologist in a recent editorial, clinical trial results are not easily translated into reliable guidance for clinical practice in which patients present commonly with multiple problems versus the strict inclusion criteria of clinical trials in which the enrolled patients have isolated conditions. ${ }^{19}$ Yet, research with administrative claims data is dependent upon the accuracy of coding in the medical claims, and incentives exist for the convenient or purposeful miscoding of medical claims..$^{20,21}$ For depression in particular, patient medical records and medical claims are not congruent. In a previous issue of JMCP, Theobald et al. found that $40 \%$ of the medical charts evaluated for patients who were prescribed an antidepressant in primary care did not document a single symptom necessary to make a diagnosis of major depression as defined by DSM-IV; another 30\% of the medical charts for patients who were prescribed antidepressants had only 1 symptom of major depression recorded. ${ }^{22}$ Only $7 \%$ of the charts had 5 of the 9 symptoms required to make a diagnosis of major depression. This study suggests that either the medical records match poorly the medical claims for the diagnosis of major depression or patients prescribed antidepressants may not have major depression as defined by DSM-IV criteria.

The data presented by Robinson et al. should also give the reader pause, particularly the finding that the percentage of patients with a diagnosis of depression and a pharmacy claim for an antidepressant who received at least 3 follow-up provider contacts in the 12-week acute treatment phase was 39.0\%, about twice the rate of $19.2 \%$ to $20.3 \%$ reported by commercial health plans in 4 consecutive measurement periods in 2001, 2002, 2003, and 2004. The significance of this finding is not immediately clear, but it is evident that either this study population received truly different care than other commercial health plans or this study population is different from the health plan members represented in 4 years of HEDIS reporting. One wonders how these factors might explain the finding by Robinson et al. that receipt of mental health specialty care was the only variable that was positively associated with greater adherence on all 4 quality measures.

Despite their finding of an above-average rate of provider contacts, Robinson et al. lament the poor performance of managed care plans in adequate medical management of depression as defined by the AMM criteria in the HEDIS quality-of-care measures. As Crownover observes in an accompanying editorial, where is the evidence to support these alleged measures of quality of care in the treatment of depression ${ }^{23}$ Is it even advisable to continue pharmacotherapy for longer than necessary to relieve symptoms of depression, particularly in persons aged 60 years or older when long-term efficacy has been demonstrated only for nortriptyline and citalopram, ${ }^{24}$ all antidepressants carry a black-box warning in labeling regarding the increased risk of suicidality in children and adolescents, ${ }^{25}$ and there is evidence of increased risk of gastrointestinal (GI) bleeding with the SSRIs? Van Walraven et al. found that the use of SSRIs increased the risk of bleeding by $10.7 \%$ for octogenarians and $9.8 \%$ for those with a history of GI bleeding. ${ }^{26}$ Low inhibition of serotonin reuptake (bupropion and most of the tricylics) in patients with a history of GI bleeding was associated with 28.6 bleeds per 1,000 person years versus 40.3 bleeds per 1,000 per years for high inhibition of serotonin reuptake (e.g., clomipramine, fluoxetine, paroxetine, and sertraline); the number needed to harm was 85 . Other research has found an association between the use of SSRIs and increased risk of GI bleeding, leading to more widespread recognition that the SSRIs, particularly the ones with more potent inhibition of serotonin reuptake, are not as safe as placebo. $^{27}$

The commercial (nongovernment) health plan scores for the AMM measures in HEDIS may suggest good or even optimum performance in the context of the evidence regarding patient response to antidepressant therapy and EBM. Mann suggests that the approach to therapy should include evaluation of the patient response to low-dose pharmacotherapy weekly or twice monthly for the acute treatment phase (6-10 weeks), with gradual dose increases depending on the clinical response and side effects and a minimum of 6 to 8 weeks to determine if antidepressant therapy will be effective. ${ }^{28}$ However, 30\% to 50\% of patients will have substantial residual symptoms after adequate first-line treatment. ${ }^{29}$ Third, absence of improvement after 4 weeks of treatment with an adequate dose of a given antidepressant medication predicts an ultimate inadequate response. ${ }^{30}$

The HEDIS measures, like all performance measures, require continuous quality improvement, and some health plans have withdrawn from HEDIS reporting. ${ }^{31}$ Kobak et al. found in their review of medical charts that reasons for failure to meet the optimal number of provider contacts in the HEDIS measure could be explained, in part, by the patient restarting a previously prescribed successful antidepressant (16\%) or a patient visit with the prescribing provider but mental health was not coded or documented in the case notes (12\%). ${ }^{32}$ Researchers at the Foundation for Accountability (FAcct) developed alternative quality and performance measures and standards in the mid-1990s to focus more closely on patient outcomes rather than processes. For example, 5-year survival rates were measured for breast cancer patients, and the outcomes from depressed patients included assessment of patient response to survey questions regarding how well they "cope," socially and emotionally, after treatment. The patient survey data for major depression in FAcct reporting are collected at 2 points, when the patient is diagnosed and 6 months later. ${ }^{33}$ 
For HEDIS quality measures in asthma management, the emphasis is placed on "the use of appropriate medication for people with asthma." The actual measure is the percentage of patients with a definition of persistent asthma who receive controller medication (methylxanthine, cromolyn sodium, leukotriene modifier, nedocromil or inhaled corticosteroid) when asthma control would be better measured by the incidence of ER visits with a primary diagnosis of asthma as a ratio of total health plan membership in person-years or as a ratio of all asthmatics as defined by International Classification of Diseases, Ninth Revision (ICD-9) codes and asthma medications. ${ }^{34}$ Asthma control has many dimensions, which include inhaler technique, adherence to prescribed regimens, patient knowledge of asthma triggers and asthma disease management, and completion of structured asthma education programs for highrisk patients. The prescription of a "controller" medication may or may not be the best asthma care for a particular patient. So, the validity of the HEDIS measure, developed in 2000 for asthma, may not measure what it purports to measure-asthma control. As for other threats to validity, the numerator of the measure (health plan members with one or more controller medications dispensed in the measurement year) does not have the same time frame as the denominator (those persons identified as "persistent" asthmatics in the year before the measurement year). Noteworthy in the HEDIS 2006 Technical Update is the instruction for health plans to "allocate the dispensing events to the appropriate year based on the date the prescription is filled, ${ }^{335}$ presumably because some plans were measuring the date-written field on the pharmacy claim rather than the date dispensed.

Aside from these issues regarding the assessment of the numerator in the quality measure, changes appear to be necessary for measurement of the denominator. Evaluation of information from 132,414 Kaiser Permanente health program patients nationwide who were included in one or more HEDIS persistent asthma study groups between 1999 and 2002 found significant error in the identification of patients with persistent asthma. ${ }^{36}$ Evaluation of electronic claims and pharmacy information revealed that $47.9 \%$ of these patients identified with persistent asthma actually had evidence of persistent asthma in only 1 of the 4 years of continuous insurance and pharmacy benefit coverage and only $28.2 \%$ had at least 3 consecutive years of evidence of persistent asthma. The results of this extensive study suggest that the current 1-year qualification period for identification of persistent asthma is inadequate and results in at least 30\% false-positive cases.

HEDIS measures emphasize underuse of health care services and ignore overuse and misuse of services. This emphasis on the underuse of services, when corrected, increases health system costs. $^{37}$ Measuring quality is important, but we need to be mindful that (a) measurement of quality should not impede quality improvement, (b) interpretation of quality scores is far from simple or even straightforward, (c) resource dollars spent in amassing data for quality measures necessarily makes fewer resources available for delivering care, and (d) quality performance measures must undergo continuous quality improvement.

\section{Asthma Disease Management-} Evidence-Based Medicine Must Be Dynamic

It seems reasonable for physicians and clinical pharmacists to protest, at least quietly, evidence-based medicine (EBM) for its potential to become cookbook medicine. ${ }^{38}$ At another level, EBM cannot be cookbook medicine because unlike recipes for cooking, the evidence in EBM is constantly changing. Perhaps, therein lies the critical distinction and the absolute need to view EBM as dynamic and continually changing as new evidence becomes available, is challenged, and survives scrutiny.

In this issue of JMCP, Heaton et al. challenge the value of leukotriene modifiers (LM) in disease management of asthma. ${ }^{2}$ Based upon the 3 clinical outcomes of emergency room visits, hospitalizations for asthma, and the use of oral prednisone ("steroid burst") to indicate exacerbation of asthma, these authors concluded that LM use was not more effective than nonuse. Worse than no improvement in these 3 clinical outcomes, LM users appeared to have more ER visits, a higher rate of hospitalization, and a higher rate of use of oral prednisone bursts. Heaton et al. calculated that LM use added $\$ 1.63$ per patient per month (PPPM) in costs (in 2002 dollars) for these 3 clinical outcomes compared with LM nonusers diagnosed with asthma.

This is no small matter for payers. The leading LM in the United States is montelukast (Singulair), which had community pharmacy sales of $\$ 1.85$ billion in 2004 , placing it at rank number 14 by expenditure among all brand-name drugs. ${ }^{39}$ The manufacturer reported that U.S. sales of montelukast increased by $10 \%$ in the third quarter of 2005 compared with the year-earlier period..$^{40}$ In the last quarter of 2005, montelukast was the number 6 drug by expenditure for a leading pharmacy benefit manager, accounting for $1.6 \%$ of total drug benefit spending among 3,010 distinct brand and generic drugs. ${ }^{41}$ Monelukast was used by 50 times more patients than zafirlukast (Accolate), the other LM, and had a discounted allowed charge per day of about $\$ 3.00$ before copayment. Some of this spending on montelukast is for allergic rhinitis-Lakomski and Chitre found that 25\% of LM utilization in 2001-2002 was not for asthma. ${ }^{42}$ Even at 75\% of current spending on montelukast, the drug ranks in the top 20 drugs in the United States, second only to combination fluticasone-salmeterol (Advair, rank number 6) among the highexpenditure drugs used in treating asthma.

Heaton et al. refer to the role of montelukast in step therapy for asthma as updated by the National Asthma Education and Prevention Program (NAEPP) in 2002. ${ }^{43}$ These 2002 asthma treatment guidelines included the recommendation of daily use of low-dose inhaled corticosteroids for mild persistent asthma as well as "low-to-medium-dose inhaled corticosteroids and 
either leukotriene modifier or theophylline" as one "alternative treatment" to the "preferred treatment" with low-to-mediumdose inhaled corticosteroids and long-acting beta2-agonists for moderate persistent asthma.

New evidence in 2005 calls these guidelines for mild persistent asthma into question. Boushey et al. found that the group of patients with mild persistent asthma randomized to no controller (inhaled corticosteroid) therapy did not have significantly poorer lung function and experienced no greater frequency of asthma exacerbation than those who received regular treatment. ${ }^{44}$ Daily budesonide (inhaled corticosteroid) was superior to intermittent budesonide therapy and to daily zafirlukast (LM) therapy in most clinical measures, including asthma control and symptom-free days in patients with mild persistent asthma, but daily zafirlukast therapy was not superior to intermittent zafirlukast therapy in any outcome. Based on these and other findings, Boushey et al. estimated that patients with mild persistent asthma may require, on average, as little as 1 course of inhaled budesonide every 2 years or oral corticosteroids once every 8 years. This symptom-driven treatment of mild-to-moderate exacerbations is a radical departure from current guidelines for treatment of mild persistent asthma. ${ }^{45}$ The cost savings from a change in treatment of mild persistent asthma from daily medication use to symptom-driven corticosteroid therapy could be large since up to $75 \%$ of asthma is mild disease. ${ }^{46}$

To put the analysis performed by Heaton et al. into additional perspective, the original drug application for montelukast provides some useful information on the clinical value of the drug. For Chronic Asthma Protocol 049, there was 4.65\% improvement in $\mathrm{FEV}_{1}$ ([forced expiratory volume in 1 second]; $8.73 \%$ for montelukast vs. $4.16 \%$ for placebo) over 8 weeks of treatment with montelukast in 198 patients versus 133 patients who received placebo). ${ }^{47}$ A more interesting finding was that the patients who received placebo experienced an average of $25.7 \%$ of days with an asthma exacerbation over the 8 weeks versus $20.5 \%$ for montelukast $(P=0.049)$. Headache determined to be drug related occurred more often in the montelukast group, $3.5 \%$ vs. $0.7 \%$ for placebo.

A meta-analysis of 1 pediatric and 12 adult clinical trials for the primary outcome of the number of exacerbations requiring systemic glucocorticoids found that patients treated with LMs were $60 \%$ more likely to require systemic glucocorticoid as a result of exacerbation of asthma symptoms compared with patients on monotherapy with an inhaled corticosteroid. ${ }^{48} \mathrm{LMs}$ were also more likely to be withdrawn as a result of inadequate asthma control (relative risk 2.5). The study concluded that $400 \mathrm{mcg}$ of beclomethasone or $200 \mathrm{mcg}$ of fluticasone is more effective than $10 \mathrm{mg}$ per day of montelukast or $20 \mathrm{mg}$ of zafirlukast twice daily.

Since montelukast is approved by the U.S. Food and Drug Administration for use in allergic rhinitis and asthma, the value of montelukast in a subset of asthma patients with allergic rhinitis is of interest. In a review of the medical literature, The Medical Letter consultants concluded in October 2005 that comparative studies with oral antihistamines and intranasal steroids are necessary, particularly since these 2 categories of therapeutic alternatives cost less than montelukast. ${ }^{49}$ The evidence of the value of montelukast in patients with a history of both allergic rhinitis and asthma is confined to a single randomized, crossover, placebo-controlled study in 52 patients with symptoms provoked by exposure to cats. ${ }^{50}$

Nathan et al. randomized 863 adult and adolescent patients who received combination fluticasone propionate salmeterol (FSC) to receive either blinded fluticasone propionate aqueous nasal spray (FPANS) 200 mcg per day or montelukast $10 \mathrm{mg}$ per day or placebo..$^{51}$ Montelukast was found to be inferior to FPANS in control of allergic rhinitis in these patients with persistent asthma treated with FSC, and the addition of either montelukast or FPANS resulted in no additional improvements in overall asthma control compared with FSC alone. These clinical data from the RCT performed by Nathan et al. in a large sample of patients with persistent asthma appear to add support to the challenge to the economic value of montelukast brought by Heaton et al. in this issue of JMCP. The evidence continues to evolve.

\section{Frederic R. Curtiss, PhD, RPh, CEBS \\ Editor-in-Chief fcurtiss@amcp.org}

\section{REFERENCES}

1. Payakachat N, Summers KH, Barbuto JP. A comparison of clinical practice guidelines in the initial pharmacological management of new onset epilepsy in adults. J Manag Care Pharm. 2006;12(1):55-60.

2. Heaton PC, Guo JJ, Hornung RW, et al. Analysis of the effectiveness and cost benefit of leukotriene modifiers in adults with asthma in the Ohio Medicaid population. J Manag Care Pharm. 2006;12(1):33-42.

3. Robinson RL, Long S, Chang S, et al. Higher costs and therapeutic factors associated with adherence to NCQA HEDIS Antidepressant Medication Management Measures: analysis of administrative claims. J Manag Care Pharm. 2006;12(1):43-54.

4. Winterbottom LM, Fong AM, Benkstein KL, Liang BB, Snodgrass LS, Parks-Huitron H. Impact of a clinical pharmacy consult service on guideline adherence and management of gabapentin for neuropathic pain. J Manag Care Pharm. 2006;12(1):61-69.

5. Hollon SD, Jarrett RB, Nierenberg AA, et al. Psychotherapy and medication in the treatment of adult and geriatric depression: which monotherapy or combined treatment? J Clin Psychiatry. 2005;66(4):455-68.

6. Nemeroff CB, Heim CM, Thase ME, et al. Differential responses to psychotherapy versus pharmacotherapy in patients with chronic forms of major depression and childhood trauma. (published online ahead of print). Proc Natl Acad Sci. 2005;100(24):14293-96.

7. Treatment for Adolescents with Depression Study (TADS) Team. Fluoxetine, cognitive-behavioral therapy, and their combination for adolescents with depression. JAMA. 2004;292:807-20.

8. Khan A, Kolts RL, Rapaport MH, Krishnan KR, Brodhead AE, Brown WA. Psychol Med. 2005;35(5):743-39.

9. Whittington CJ, Kendall T, Fonagy P, et al. Selective serotonin reuptake inhibitors in childhood depression: systematic review of published versus unpublished data. Lancet. 2004;363:1341-45. 
10. Emslie GJ, Rush AJ, Weiberg WA, et al, A double-blind, randomized, placebo-controlled trial of fluoxetine in children and adolescents with depression. Arch Gen Psychiatry. 1997;54:1031-37.

11. Emslie GJ, Heiligenstein JH, Wagner JD, et al. Fluoxetine for acute treatment of depression in children and adolescents: a placebo-controlled randomized clinical trial. J Am Acad Child Adolesc Psychiatry. 2002;41:1205-15.

12. Thase ME, Haight BR, Richard N, et al. Remission rates following antidepressant therapy with bupropion or selective serotonin reuptake inhibitors: a meta-analysis of original data from 7 randomized controlled tirals. J Clin Psychiatry. 2005;66(8):974-81.

13. Hjalmarsson L, Corcos M, Jeammet P. Selective serotonin reuptake inhibitors in major depressive disorder in children and adolescents (ratio of benefits/risks). Encephale. 2005;31(3):309-16.

14. Kahn A, Brodhead AE, Kolts RL, Brown WA. Severity of depressive symptoms and response to antidepressant and placebo in trials of antidepressants. J Psychiatr Res. 2005;39(2):145-50.

15. Khan A, Brodhead AE, Schwartz KA, Kolts RL, Brown WA. Sex differences in antidepressant response in recent antidepressant clinical trials. J Clin Psychopharmacol. 2005;25(4):318-24.

16. Corey-Lisle PK, Nasch R, Stang P, Swindle R. Response, partial response, and nonresponse in primary care treatment of depression. Arch Intern Med. 2004;164:1197-1204.

17. Eaddy MT, Druss BG, Sarnes MW, Regan TS, Frankum LE. Relationship of total health care charges to selective serotonin reuptake inhibitor utilization patterns including the length of antidepressant therapy: results from a managed care administrative database. J Manag Care Pharm. 2004;11(2):145-50.

18. Simon GE, Ludman EJ, Tutty S, et al. Telephone psychotherapy and telephone care management for primary care patients starting antidepressant treatment-a randomized controlled trial. JAMA. 2004;292:935-42.

19. Ruthven L. Where is the proof that polypharmacy is effective? Drug Benefit Trends. December 2005;554, 557.

20. Barbuto JP. Categorizing patients from medical claims data-the influence of GIGO. J Manag Care Pharm. 2004;10(6):559-60.

21. Curtiss FR. Evidence-based medicine: beware of results from randomized controlled trials and research with administrative claims data. J Manag Care Pharm. 2005;11(2):172.

22. Theobald DE, Kasper M, Nick-Kresl CA, et al. Documentation of indicators for antidepressant treatment and response in an HMO primary care population. J Manag Care Pharm. 2000;6(6):494-98.

23. Crownover BK. Referral bias and other perspectives on the HEDIS measuring stick for quality of care in depression treatment. J Manag Care Pharm. 2006; 12(1):76-77.

24. Petrovic M, De Paepe P, van Bortel L. Pharmacotherapy of depression in old age. Acta Clin Belg. 2005;60(3):150-56.

25. FDA Public Health Advisory-Suicidality in children and adolescents being treated with antidepressant medications. October 15, 2004. Available at: http://www.fda.gov/cder/drug/antidepressants/SSRIPHA200410.htm. Accessed December 26, 2005.

26. van Walraven C, Mamdani MM, Wells PS, Williams JI. Inhibition of serotonin reuptake by antidepressants and upper gastrointestinal bleeding in elderly patients: retrospective cohort study. BMJ. 2001;323:655-58.

27. Curtiss FR. Evidence-based medicine: are SSRIs more effective than placebo and what length of therapy is enough? J Manag Care Pharm. 2005;11(2): $172-76$.

28. Mann JJ, Drug therapy. The medical management of depression. N Engl J Med. 2005;353:1819-34.

29. Amsterdam JD, Maislin G, Potter L. Fluoxetine efficacy in treatment resistant depression. Prog Neuropsychopharmacol Biol Psychiatry. 1994;18:243-61.

30. Rush AJ, Kupfer DJ. Strategies and tactics in the treatment of depression. In: Gabbard GO, ed. Treatment of Psychiatric Disorders. 3rd ed. Washington, D.C.: American Psychiatric Press; 2001:1417-39.
31. McCormick D, Himmelstein DU, Woolhandler S, Wolfe SM, Bor DH. Relationship between low quality-of-care scores and HMOs' subsequent public disclosure of quality-of-care scores. JAMA. 2002;288:1484-90.

32. Kobak KA, Taylor L, Katzelnick DJ, Olson N, Clagnaz P, Henk HJ. Antidepressant medication management and Health Plan Employer Data and Information Set (HEDIS) criteria: reasons for nonadherence. J Clin Psychiatry. 2002;63(8):727-32.

33. Kertesz L. Group aims to raise comparison standards. Mod Healthcare. July 8, 1996:46,48,

34. Glauber JH. Does the HEDIS asthma measure go far enough? Am J Manag Care. 2001;7(6):575-79.

35. National Committee for Quality Assurance (NCQA). HEDIS 2006. Vol. 2. Technical Update. October 1, 2005. Available at: http://www.ncqa.org/Programs/ HEDIS/2006/Volume2/TechnicalUpdate.pdf. Accessed December 26, 2005.

36. Mosen D, Macy E, Schatz M, et al. How well do the HEDIS asthma inclusion criteria identify persistent asthma? Am J Manag Care. 2005;11(10):650-54.

37. Bodenheimer T. The American health care system-the movement for improved quality in health care. N Engl J Med. 1999;340(6):488-92.

38. Oetgen WJ, Wiley MJ. Medical practice guidelines: is cookbook medicine here? Available at: http://72.14.203.104/search?q=cache:QtPrxBcseNgJ: www.afip.org/Departments/legalmed/openfile96/guidelines.pdf+cookbook+ medicine\&hl=en. Accessed December 18, 2005.

39. Data from Verispan. Top 200 brand-name drugs by retail dollars in 2004 Drug Top. February 21, 2005:18.

40. Merck \& Co., Inc. Other financial disclosures, third quarter 2005. Available at: http://ibrary.corporate-ir.net/library/73/731/73184/ items/170444/3Q05_other.pdf. Accessed December 26, 2005.

41. Data search performed December 20, 2005, of the data warehouse of a national pharmacy benefits manager representing approximately 500,000 beneficiaries of small employer drug benefit plans for pharmacy claims with dates of service from October 2005 through December 15, 2005.

42. Lakomski PG, Chitre M. Evaluation of the utilization patterns of leukotriene modifiers in a large managed care health plan. J Manag Care Pharm. 2004;10(2):115-21.

43. National Asthma Education and Prevention Program (NAEPP) Expert Panel Report: Guidelines for the diagnosis and management of asthmaupdate on selected topics 2002. Available at: http://www.nhlbi.nih.gov/ guidelines/asthma/index.htm. Accessed December 18, 2005.

44. Boushey HA, Sorkness CA, King TS, et al. for the National Heart, Lung, and Blood Institute's Asthma Clinical Research Network. N Engl J Med. 2005;352:1519-28.

45. Fabbri LM. Does mild persistent asthma require regular treatment? N Engl J Med. 2005;352:1589-91.

46. Auerbach I, Springer C, Godfrey S. Total population survey of the frequency and severity of asthma in 17 year old boys in an urban area of Israel. Thorax. 1993;48:139-41.

47. FDA Center for Drug Evaluation and Research. Application \# 20-830, Medical Reviews. Medical Officer Review, January 20, 1998. Available at: http://www.fda.gov/cder/foi/nda/98/20830_Singulair_medr.pdf. Accessed December 18, 2005.

48. Ducharme FM. Inhaled glucocorticoids versus leukotriene receptor antagonists as single agent asthma treatment: systematic review of current evidence. BMJ. 2003;326:621-25.

49. Montelukast (Singulair) for perennial allergic rhinitis. Med Lett. 2005;47 (1220):87-88.

50. Perry TT, Corren J, Phillip G, et al. Protective effect of montelukast on lower and upper respiratory tract responses to short-term cat allergen exposure. Ann Allergy Asthma Immunol. 2004;93(5):431-38.

51. Nathan RA, Yancey SW, Waitkus-Edwards K, et al. Fluticasone propionate nasal spray is superior to montelukast for allergic rhinitis while neither affects overall asthma control. Chest. 2005;128(4):1910-20. 